\title{
Game Analysis of Dynamic Planning Evolution for the Optimization of Community Governance Structure in Smart Cities
}

\author{
Gaofeng Liang \\ Chongqing Jiaotong University, Chongqing 400074, China \\ Correspondence should be addressed to Gaofeng Liang; 990020040658@cqjtu.edu.cn
}

Received 22 February 2021; Revised 27 March 2021; Accepted 7 April 2021; Published 16 April 2021

Academic Editor: Wei Wang

Copyright (c) 2021 Gaofeng Liang. This is an open access article distributed under the Creative Commons Attribution License, which permits unrestricted use, distribution, and reproduction in any medium, provided the original work is properly cited.

\begin{abstract}
In this paper, we study the structural optimization of community governance in smart cities and optimize the structure based on the game analysis of dynamic planning evolution. Theoretically, the connotation and extension of the concept of "self-organization" are cleared, and the environment and conditions of community self-organization formation, the formation process of community self-organization, and the types of community self-organization are discussed. The so-called "self-organization" is a process of spontaneously moving from disorder to order, and the environment and conditions of community self-organization are mainly the openness, nonequilibrium state, and nonlinearity of the system. The key parameters of the contract with the change of the values of each factor make up for the inability to collect data for the empirical study in this paper; then, it presents four linear stages along with the cause such as self-creation, self-expansion, self-maintenance, and self-degeneration, respectively. The types of community self-organization mainly include community self-organization with random aggregation, socialized community self-organization, and stable community self-organization with autonomy orientation. By systematically sorting out the relationship between community self-organization and government, while confirming the positive significance of community selforganization to community cultural governance, various complex conflicts and game relationships will deeply affect the actual effectiveness of cultural governance and provide useful knowledge reference for future community cultural governance.
\end{abstract}

\section{Introduction}

To build a service-oriented government, intelligent community governance has been strengthening the enhancement of services, solving the problem of decentralized interests of subjects, improving the level of governance by introducing the model of shared governance of multiple subjects, and fully manifesting the main role of people in grassroots governance [1]. The research results show that intelligent community governance needs to coordinate the interests of various subjects, and the cooperation of multiple subjects is the basic requirement to improve the community governance system. The second is that the Urban Real Estate Management Law and the Property Law endow community residents with varying degrees of personal property rights, but there are no regulations on the management and use of shared property, which leads to a lack of awareness of the residents' responsibility for the management and maintenance of shared land and public property. Using the evolutionary game analysis method, we explore the current situation and mode of community governance in which multiple subjects in intelligent communities participate together [2]. The government department implements the basic guideline of serving the people, vigorously regulates the service-oriented government system, acts as an executor in urban community management, effectively controls community governance by a macro allocation of resources and policy support through intelligent means, brings into play the functions of government departments, and improves the efficiency and governance level [3]. In community governance, the government mainly applies measures such as policy support, institutional arrangement, and resource integration, specifically including the formulation of relevant policies and systems, rational allocation of community resources, and coordination of interests of all parties. 
The innovation of social governance structure studied in this topic tries to make a breakthrough at three levels: First, the reform of any era needs to find the corresponding thinking origin, which is not only the basis of the logical extension but also the source of ideological expansion [4]. From a chronological perspective, the logical starting point of governance reform has gone through development from imaginary order to natural order and then to rational order. The order here originates from human thinking about all things in the universe and is an understanding and expression of a holistic concept [5]. There are two main situations of grassroots autonomy, namely, urban community autonomy and rural area autonomy. However, as the process of urbanization and industrialization accelerates, the original urban community autonomy is subject to "rights impact," and rural area autonomy is subject to "interest challenge." The study of social governance development needs to construct a two-way interactive structure theory, and this study tries to make a useful attempt here. The combination of multiple participation, intelligence, collaborative governance, and community aging makes the system appear new components and characteristics; based on various new components, it constitutes the framework of collaborative governance of intelligent urban community aging and the relationship between the components of the new framework and the original parts [6].

From the perspective of the evolution of urban spatial patterns, urban expansion has become the main way of urbanization. With the accelerated spreading of urban space from the central area to the peripheral area, the land structure, industrial structure, population structure, and functional structure of the urban peripheral area have changed significantly. The boundary between urban and rural areas has become blurred in the urban fringe, and the urban-rural interface has become a synonym for the urban fringe and a transition zone between urban and rural areas. For urban development, the urban-rural interface has an important role in land reserve, factor aggregation, facility bearing, and ecological barrier. How to give full play to the comparative advantages of urban-rural areas and support urban development and urban-rural integration process through the implementation of functional positioning of urban-rural areas has become a key and difficult issue of urbanization. Why are rights impacting the autonomy of urban residents? First, with the urban demolition and reconstruction and the increasing concentration of migrants, the original urban community population structure has undergone a fundamental change, and groups from different regions and different strata constitute a new community. The reason caused the impact of the autonomy of the "acquaintance social master" type residential (home) committee in urban communities in the planned economy era.

\section{Related Studies}

$\mathrm{Xu}$ suggests that based on the trend of richness and extensiveness of social network development, the administration is called upon to use intelligent means to collect multiple types of data in the community, to implement proactive innovation in the administration, and to actively experience the reasonable ideas and needs of community residents to expand the coverage of public services [7]. Bibri and Krogstie suggest that the smart network governance approach makes community governance democratic and effective [8]. Smart community governance makes reasonable use of the Internet platform to enrich the multiple experiences of community residents in smart living and joy in the community XI [9]. Sookhak et al. pointed out that the construction of smart communities covers the daily needs of residents such as government, medical care, and education, and the wisdom facilities link the daily lives of residents, gradually replacing the traditional fixed work and study mode and effectively driving the residents' life [10]. The intelligent facilities will gradually replace the traditional fixed working and learning mode and effectively lead to the change of residents' lifestyle. Smart community management should start from meeting the needs of residents and gradually radiate the daily needs of community residents.

Javadzadeh revealed the applicability of social governance, being the first to analyze organizational theory and institutional theory of governing public things and apply them to practical governance [11]. Xie et al.'s theory of community interaction research shows that communities, as voluntary interoperable management systems of residents, use diverse community organizations, assign diverse roles for community activities, and improve the slow development of community governance, thus satisfying the diverse needs of residents to promote the dynamic development of the community and ensure the normal and stable functioning of the community [12]. Community building has improved the environment where local autonomy is difficult to achieve, and community governance has gradually shifted from pure domination to the development of pluralistic governance changes [13]. Collaborative governance, as the focus of foreign governance theories, has achieved general resonance among scholars, highlighting the comanagement and corule of public affairs in the process of social management, mainly highlighting the characteristics of collaboration and cooperation, which is very similar to pluralistic corule and polycentric governance [14]. Eckhoff was the first to use the meaning of collaborative governance and identified it as a special multisubject collaborative model of dealing with affairs [15]. The subjects involved in governance are pluralistic; based on certain group of behavior requirements, each subject is detached from each other's common constraints, independently receives the responsibility of governing public affairs, adjusts the relative inhibition of developing relationships, builds a polymorphic management system of joint participation, and evolves into a perfect community cogovernance system of multiple subjects such as government and society [15].

The primary feature of the theory of service-oriented government is to establish the fundamental concept of government serving the public and safeguarding the interests of the whole. Firstly, it maintains the basic characteristics of developing people's life, puts people's interests in the main position, provides appropriate services according to the specific requirements of the public, and enhances the 
degree of access of the public. Secondly, with the fundamental concept of supplying public daily services to the satisfaction of the people, the government enhances the integrity of the social system, optimizes the social environment, ensures the supply of resources, fosters the construction of community services, and drives social development following the actual situation of urban development. Evolutionary game theory does not strictly delineate the participating subjects ; by determining the behavioral strategies of the participants, we can modify the fixed cognition of the strategies in the evolutionary process and further optimize the specific institutional standards.

\section{Dynamic Planning Game Community Structure Optimization Analysis}

3.1. Dynamic Programming Game Design. The concept of "evolutionary stable strategy" was first proposed by Smith and Price. As the game is played, again and again, the majority of the individuals in the group gradually prefer stable strategies, and even if there is a small group of strategy changes, they will fade away because the benefits of the changes are less than the average benefits of the original strategy, and the equilibrium state of the system is not broken. If there is no strong shock from outside, the system itself will not deviate from the stable state, and its strategy will not produce changes. This equilibrium stable state is called evolutionary stable equilibrium, and the corresponding strategy is called evolutionary stable strategy (ESS). Conversely, if the small group produces changes, the change in the return is greater than the average return of the original strategy. The original equilibrium state of the system is broken. A large proportion of individuals will gradually tend to choose a higher return strategy; low return strategy is discarded, through continuous evolution, until no more changes in the strategy can disturb the steady state of the entire system. The current system strategy is optimal [16]. That is, the evolutionary stability strategy is through the game parties to repeatedly imitate and improve the game activities; all the parties gradually tend to choose a stable strategy. The evolutionary stabilization strategy is a good reflection of the biological evolutionary law of "survival of the fittest."

In the evolutionary game analysis, the evolutionarily stable strategy is a static stable state, while the replicated dynamic equation is a dynamic change trajectory with dynamics principles. The replication dynamic equation is a mathematical analysis method to study the dynamic change process of the game subject through the repeated game and finally reach the equilibrium strategy. The game subject is not completely rational; they are interest driven. When the game party is to take the strategy of lower returns, they will spontaneously choose (imitate) the strategy with higher returns, so that the proportion of the game group to choose a strategy will change, with $x$ representing the proportion of the game party to choose a strategy. The rate of change of the proportion of strategy $x$ is proportional to the proportion of individuals in the group and proportional to the extent to which the gain from choosing the strategy is greater than the average gain of the group, so it can be expressed by the following differential equation:

$$
\frac{\mathrm{d} x}{\mathrm{~d} t}=x\left(\mu_{0}-\mu_{1}^{2}\right) .
$$

There is no strategy imitation and the game system is in a relatively stable state. However, the strategy corresponding to the equilibrium point is not necessarily evolutionarily stable. These stable points can only indicate that the proportion of participants in the game will not change when they choose a particular strategy, but they do not indicate the final dynamic tendency [17]. Also, the equilibrium stable strategy needs to have a certain antidisturbance, even if there is a small perturbation so that the ratio $x$ deviates from the equilibrium point. It can be quickly adjusted back in the subsequent repeated game process; that is, the strategy corresponding to the equilibrium point is the strategy with the best relative return.

Each game subject can decide to maximize his interests based on the information known to him. In fact, due to the cognitive factor of the game participants, there is rarely a completely rational situation, and the evolutionary game takes this factor into account and improves the shortcomings of traditional game theory, incorporating finite ideals into the game framework, and the final game results of the game participants can only be a certain stable state. The evolutionary game theory believes that the research subject has two characteristics of finite rationality and learning ability because the participating subjects have the characteristics of finite rationality, so the game group of a certain scale cannot find the optimal strategy through a single game and needs to learn, imitate, and improve continuously to finally find the optimal decision to maximize their interests. The evolutionary game has two core concepts, namely, the evolutionary steady-state ESS and the replication dynamic equation.

$$
\begin{aligned}
F(k) & =x_{k}[\mu(k, s)-u(s, s)]+k, \\
E_{x e} & =p \times E_{11}+(1-p) E_{12} R_{1}-C_{1} .
\end{aligned}
$$

This is confirmed in practical situations, and although disequilibrium is an important condition for community formation and is the beginning of the system's movement from disorder to order, it is important to note here that this does not mean that the higher the disequilibrium of the community is, the easier it is for community self-organization to form. The imbalance is only a condition for the formation of self-organization, but it is also difficult to form self-organization when the imbalance of the community is caused by the poor economic situation of the residents. In the actual research, we learned that the quantity and quality of self-organization in communities with relatively poor economic conditions are much lower than those communities with relatively good economic conditions. Such communities tend to have more unstable factors and are more prone to violence such as theft and robbery, and the residents are more likely to put basic human needs such as survival and safety first, which is more difficult for the government to manage. 
All residents are driven into joining community governance. The community residents' committee gets close to the residents' daily lives, uses its influence to attract community residents to manage the community's prosperity, jointly studies community public affairs and factors that affect the residents' experience, safeguards the true interests of community residents, and achieves the goal of joint governance of the community by multiple subjects.

$$
x=\frac{\left(a_{1}-k_{1} t\right)-\left(a_{2}-s\right)}{\left(a_{1}-k_{1} t\right)-\left(a_{2}-s\right)+k_{1}^{2} t} .
$$

The participants in the demolition and relocation activities in urban and rural areas include the demolition party and the demolished party. The participants bargain over the compensation for demolition and relocation and make decisions to maximize benefits, and the task of the thirdparty organization is to coordinate the two parties, conduct information, give a ruling proposal, and end the bargaining process. The government is the demolition party in the demolition activity and the rule-maker of the game before the third party intervenes, and the residents are the demolished party in the demolition activity. The information set of the demolisher contains its characteristics, the cost of each offer, the corresponding benefit, the offer of the other party in the previous round, the characteristics of the demolished party, and the cost and benefit of the other party inferred from the information of the demolished party's offer; the information set of the demolished party corresponds to the same. In the first stage, the government acts as the demolisher first and waits for the demolished person to respond. If the demolished person agrees to the demolisher's proposal, the game ends, and if he does not agree, the game will proceed to the second stage. Assuming that a third-party organization is involved, a mandatory and effective proposal is formulated based on the demands of both sides of the game, and both sides of the demolition are satisfied with the offer results, so the game ends.

$$
J=\left[\begin{array}{ll}
\frac{\partial G(x)}{\partial x} & \frac{\partial G(x)}{\partial y} \\
\frac{\partial G(y)}{\partial x} & \frac{\partial G(x)}{\partial y}
\end{array}\right]
$$

Through adjustment of pension-related policies, systems, and planning of multiparty coordination, the government focuses on solving pension problems by adjusting and formulating new related policies to solve a certain problem in pension. In the process of formulating related policies for consultation, the government generally adopts new consultation mechanisms such as hearings and extensive consultation, i.e., multiparty coordination mechanisms and feedback mechanisms, due to the widespread concern. In this mode of communication, people are allowed to express their opinions, and various ideas and demands can be fully expressed and conveyed. At the same time, the government and related departments will also seek opinions from the supply sector of senior care services, especially on how to improve the level of senior care supply, which makes the feedback mechanism further evolve, as shown in Figure 1.

System dynamics is an effective way to combine qualitative and quantitative aspects to study the connections between the intrinsic units of a system and the way they are influenced. The system's understanding of the problem is based on the close connection between the intrinsic mechanisms of the system's behaviour. By observing the feedback information of the system and building a mathematical model, we can step by step discover the correlation between behaviours and the cause-and-effect relationships that produce changes. System dynamics model is a rational model that searches for causal mechanisms, and by studying the internal influence mechanisms of the system and tracing the causes of changes, system dynamics can be applied to many complex system problems with long-term, periodic, and dynamic nature, mainly used to predict, simulate, plan, and manage social, economic, political, physiological, natural, and other types of system problems.

System dynamics view the problem or object to be studied as a system of fluid motion, and the system consists of three basic parts: units, motion, and information. The units are distinct from each other yet interconnected, organically united in a certain environment, and move under the influence of information to form a specific behaviour pattern. The behaviour of the system is mainly determined by the internal structure of the system and the corresponding feedback mechanism. In other words, under certain conditions, changes and perturbations in the external environment can have an important impact, but the occurrence and development of system behaviour essentially depend on the internal system.

As an important channel to maintain the communication between community residents and the government, the community council can reflect the needs of all residents exactly, effectively convey the wishes and demands of community residents, and ensure the common interests of community residents by integrating their inevitable needs. It resolves conflicts among community residents, promotes the formation of harmonious social relations, and effectively builds a high-quality public environment.

3.2. Structural Optimization Design Analysis of Smart City Communities. These voluntary groups are relatively small and maintain a close relationship with the neighborhood councils, which also need these voluntary organizations as a supplement to the government management to help provide some help and services to the disadvantaged groups in the community. Some community volunteering teams are led directly by the leaders of the neighborhood committees, and most of their members are party members in the community. This is difficult to avoid, as only the neighborhood committee can understand the specific situation of each household in the community and know which residents need help and what kind of help they need, according to the community staff. The development of community self-organization comes from the awakening of community 


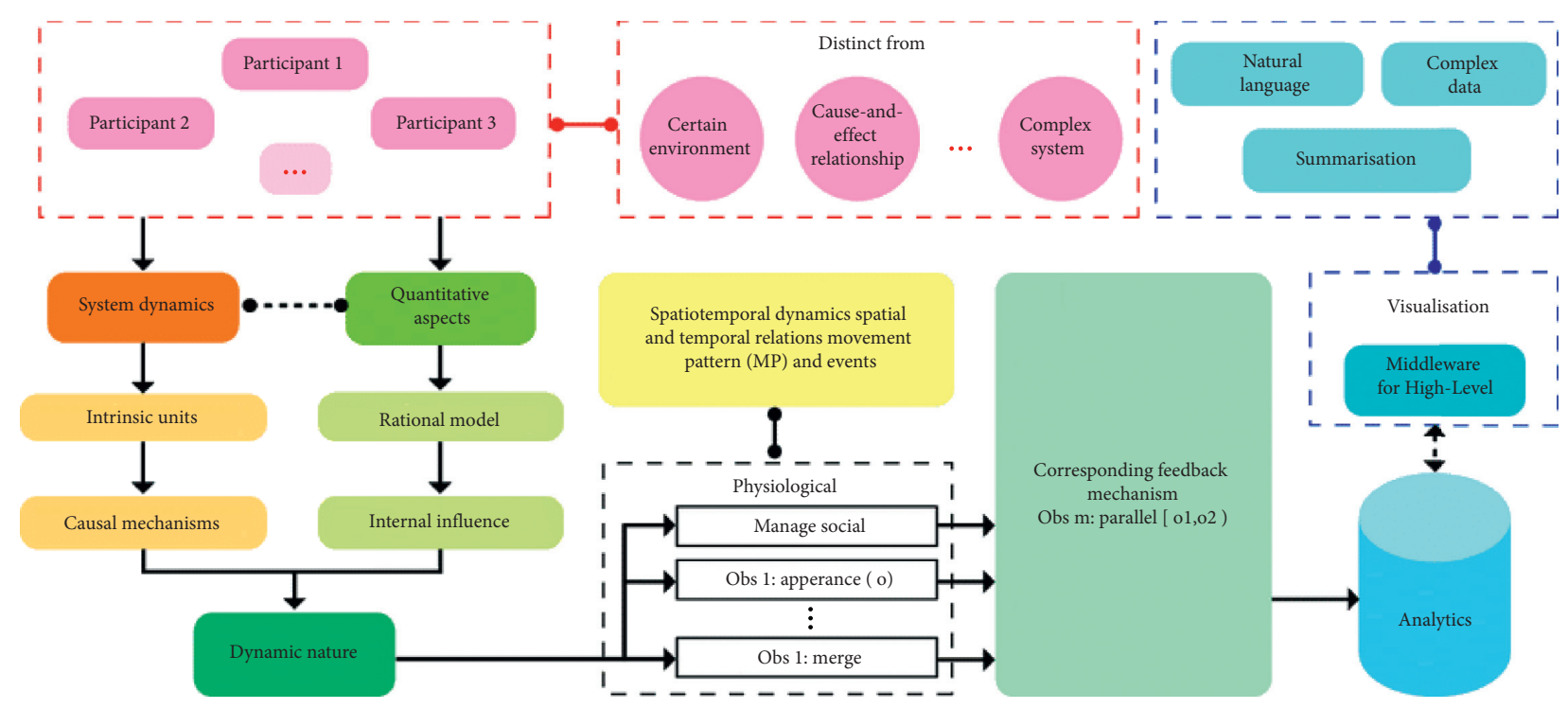

Figure 1: Dynamic planning game analysis architecture.

residents' awareness of self-service and self-management. Both self-help organizations and voluntary organizations are consciously and unconsciously solving the problems faced by themselves and others, reflecting the residents' willingness and enthusiasm to participate.

To further improve the urban grid management system of the street, we upgraded and renovated the original grid system of the street and expanded the business applications of the street based on the interface with the new grid system. Intelligent management is the core of urban management mode; the street city transportation centre developed "community wisdom eye" to collect and summarize all garbage cans in residential areas and stores along the street, such as the location, quantity, capacity, putting time, and number of times.

At present, the development of intelligent communities mainly relies on the economic and technical support provided by the government in various aspects, and the existing community construction generally relies excessively on government support, making it difficult to get rid of the government-led situation. In community governance, residents can use technology to establish connections with the community, society, and enterprises to express and give feedback on their opinions about community public affairs. The meanings of $\$ / m_{-} \_\$$ and $\$ / m u \_1 ~ \$$, respectively, represent the corresponding state parameter values in states 0 and 1 . In promoting intelligent community governance, however, the lack of professional capacity, constraints by the time and space conditions of fast-paced life and work, and insufficient information disclosure have all led to the fact that the role of communities as assistants in government affairs has not changed much, and the disconnection between community services and residents' needs still exists. To make the community develop rapidly, we cannot rely on the power of the government alone but should make full use of social resources, introduce third-party social organizations, and promote the participation of the government, social organizations, enterprises, and residents in community governance in the form of government purchase of public services. Community residents play the role of community ownership and change from being the enjoyers of community public services to being the providers, while the government should play more of a coordinator role in community governance.

Not only does the intelligent construction of a community based on IoT bring a cognitive revolution and governance revolution, but the long-term significance of IoT community operation also lies in big data collection. Through big data cell phones, the effective use of social resources can be realized; at the same time, the privacy and security of individuals in the context of the big data era deserves the attention of the whole society. After data collection, a regulatory system should be established for the production, use, and management of data. The current adoption of this model involves a high level of information security. With the progress of society, a new pattern of pluralism and diversity of subjects is taking shape [18]. The government is no longer the only actor in social management; although the government plays a leading role, playing its influential role, no longer regulation and control, the government, social organizations, enterprises and citizens, and other social multiple subjects play an increasingly important role in the management of public affairs as well as decision-making in a consultative and cooperative, interactive and collaborative manner, forming a new type of relationship in the process of participation of multiple forces. Optimal design of smart city community structure was shown in Figure 2. The main reason why this system structure is most suitable for the community structure is its low cost, quick results, and low technical threshold that can be achieved.

The exploration of intelligent applications is conducive to consolidating the party's ruling base. The research finds out the order parameters for the orderly operation of the information system and gives a quantitative method for the order parameters. Based on the two, the mapping 


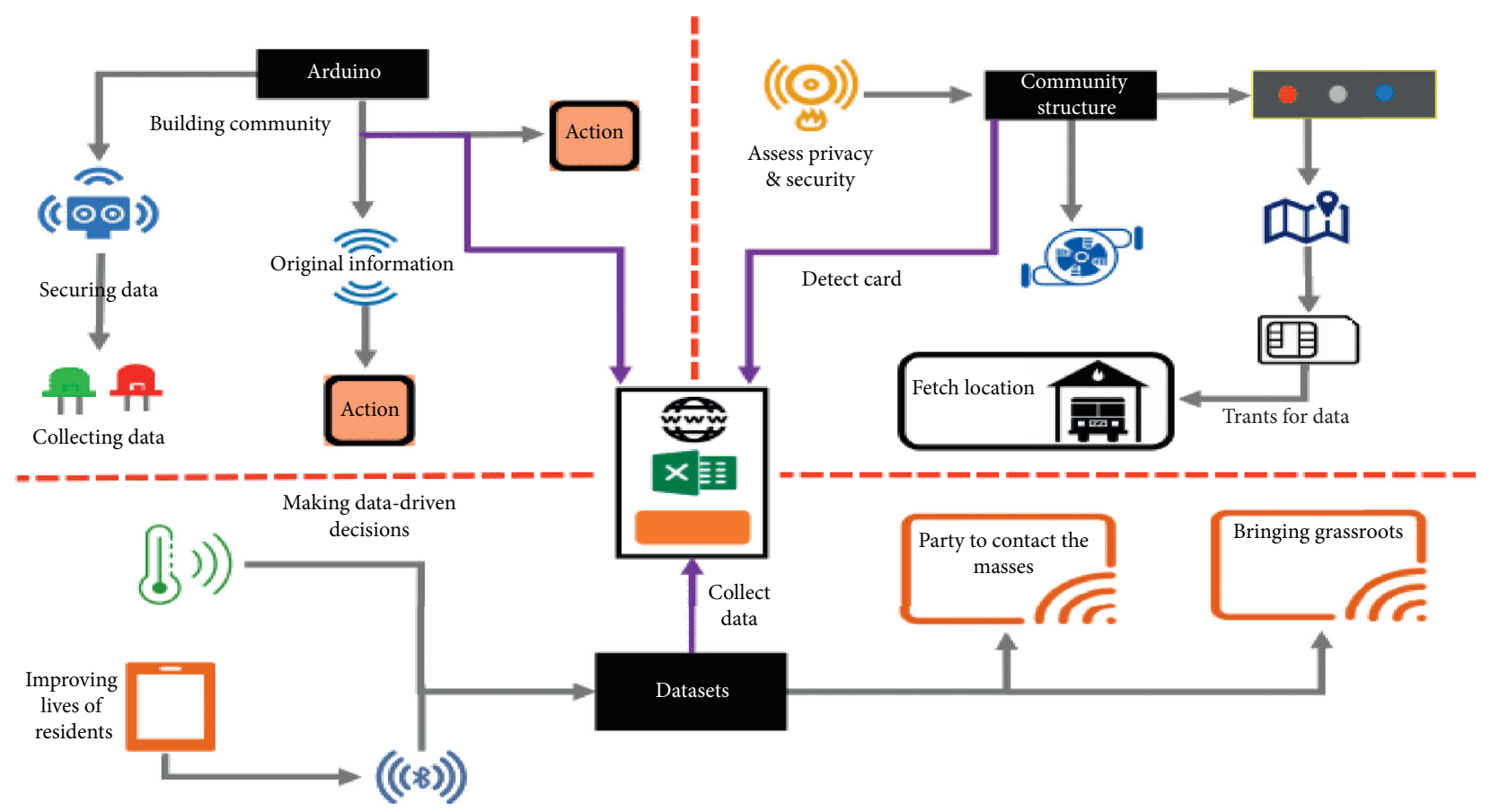

Figure 2: Optimal design of smart city community structure.

relationship between the changes of external environmental factors and the order parameters of the information system is established. The organization adapts to the changing process of external environmental factors, gives a servo constraint function, and discusses the algorithm of the selforganization process in detail. The construction of the intelligent system innovates the way for the party to contact the masses and take root at the grassroots, which is conducive to bringing grassroots party organizations closer to the people, using the network platform to obtain the most real and original information of the grassroots, grasping the demands of the masses in time, strengthening the interaction with the people, broadening the channels for expressing the interests of the masses, and enhancing the scientific and democratic nature of decision-making. Intelligence reduces the cost of urban community governance refinement with process optimization. Information technology has changed the traditional way of information communication [19-22].

Through intelligent technical means, the data in the areas of public management and public services of districts, streets, towns, and communities are integrated and opened up, forming a grassroots information pattern of regional interaction, information interconnection, and data sharing, bridging the barriers within the government and between lines, and between the government and enterprises and social organizations and residents with information technology, reconstructing an efficient and convenient workflow [23]. The information sharing among different industries and government departments will enhance the service capability and collaborative governance capability of government departments.

Through intelligent technology, we promote the participation of diversified subjects. In the grassroots governance, the organization plays a central role and the neighborhood committee dominates, but the residents' awareness of the "main body" and the ways to achieve it need to be strengthened. It is necessary to build an effective platform to promote the participation of multiple subjects, expand the participation and depth of participation, and promote the implementation of intelligent technology for consultation and democracy to serve the community, so that residents in the community can benefit from it and feel the efficient governance, thus enhancing their sense of identity and belonging to the community. The concept of "intelligent community governance" can be divided into two stages. One is the stage of adopting intelligent hardware. In recent years, with the application and popularization of intelligent technology and means in the community, online work and electronic office have become a work norm. Through the use of intelligent technology, various government resources, facilities and equipment, community personnel, business units, public opinion information, and other information resources are integrated to achieve electronic processing of community data, automation of community offices, intelligent management of community affairs, etc., to facilitate a comprehensive grasp of the community's daily management and service work.

\section{Analysis of Results}

4.1. Analysis of Simulation Results. In this article, we designed the value of $x$ to be 0.75 and the value of $y$ to be 0.75 . Our parameters include these two parameters. Take $x=0.75$ and $y=0.75$ as the initial state of the game and conduct the first simulation of the evolution of the game; the results are shown in Figure 3. 
The initial state assumes that $y=0.75$, the probability of regulation is higher, and the enterprise is more likely to provide high-quality service; let $x=0.75$. In the early stage of cooperation, the community will gradually relax the regulation because of the enterprise's high-quality service, and the enterprise will improve its service quality in a short period because of the community's high regulation, which is about 0.5 years; after that, the enterprise quickly understands and learns the community's regulation strategy and opportunistically reduces its service quality; after the enterprise's service quality decreases to a certain value, the community realizes that high regulation will gain more benefits, so it gradually improves the regulation. From the simulation curve's twists and turns, both communities and enterprises have a certain time lag in accessing information, and both parties cannot predict each other's actions in advance, nor can they make strategy changes at the same time, but one party gradually evolves its strategy according to the impact and results of the strategy adopted by the other party. With the repetition of the game in the cooperation cycle, the strategy fluctuation of both parties gradually decreases and tends to be stable. Community supervision will be fixed at a certain frequency, and the service quality of senior canteens will gradually tend to a certain stable level, and the operation will be stable and good.

Substitute $x=0$ and $y=0$ as the initial state of cooperation into the simulation software, at which time the enterprise and the community will maintain a bad stable state. Consider the community's regulatory probability of +0.1 abrupt change at time $=0.2$ due to the request of higher government or public opinion feedback, whose simulation is shown in Figure 4.

Suppose the community is dissatisfied with the current operation of the senior cafeteria and chooses to increase the frequency of regulation, $y$ generates an upward mutation, and the enterprise also makes strategic adjustments targeted by the high frequency of regulation mode; the equilibrium state is broken. When the community observes the action of the enterprise to improve the service quality, it starts to relax the regulation, and then the enterprise will slowly reduce the service quality under the relaxed regulatory environment. Despite the fluctuation of the early cooperation, the fluctuation becomes smaller and smaller as the cooperation deepens, and after a certain period (about 8 years), the socialenterprise cooperation returns to the original state" equilibrium state again, without breaking the overall equilibrium trend because of the small sudden changes. The deadlock of "reduce and strengthen supervisionservice quality improvement-relaxation of supervision" will develop in a stable direction.

The evolutionary stability results of the system depend on the initial values and variations of the decision parameters, and the MATLAB 7.0 is applied to solve the replication dynamic equations (4) and (6) with parameter values initialized as shown in Figure 5 and obtain the dynamic evolution diagram of the system, where the horizontal axis represents the evolution time of the system $t$ and the vertical axis represents the proportion of active regulation by the

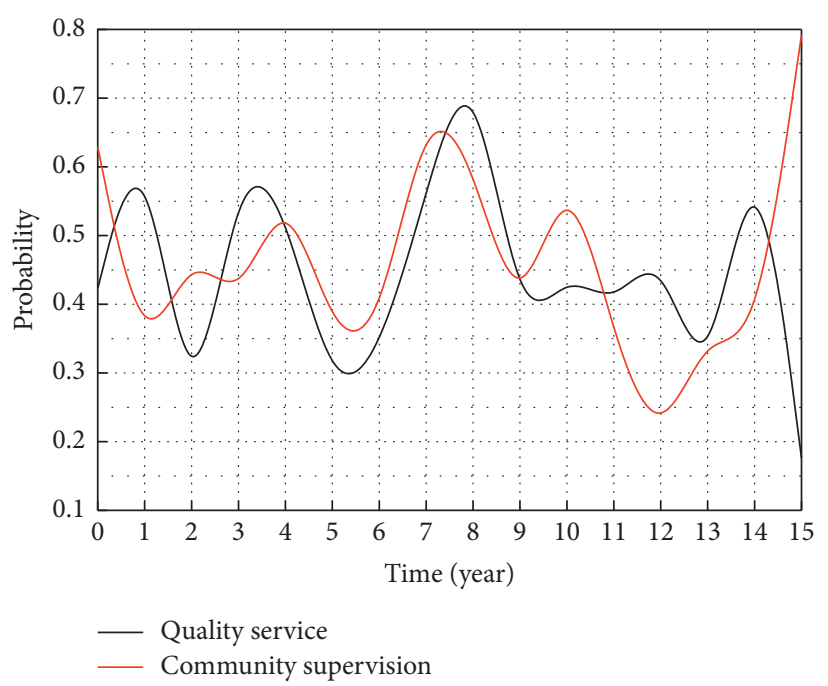

Figure 3: Initial simulation diagram.

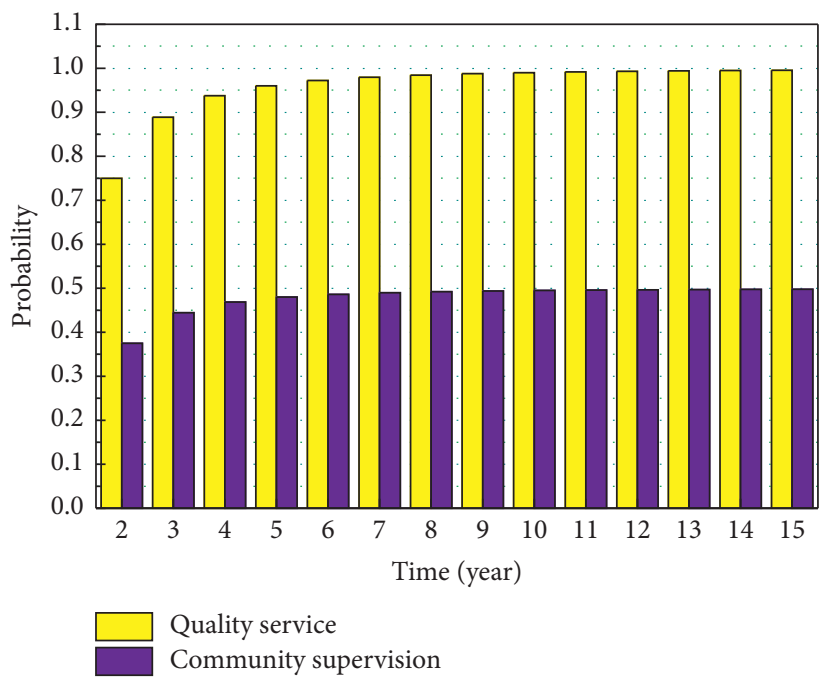

FIgURE 4: Simulation diagram of the evolution of equilibrium point mutation.

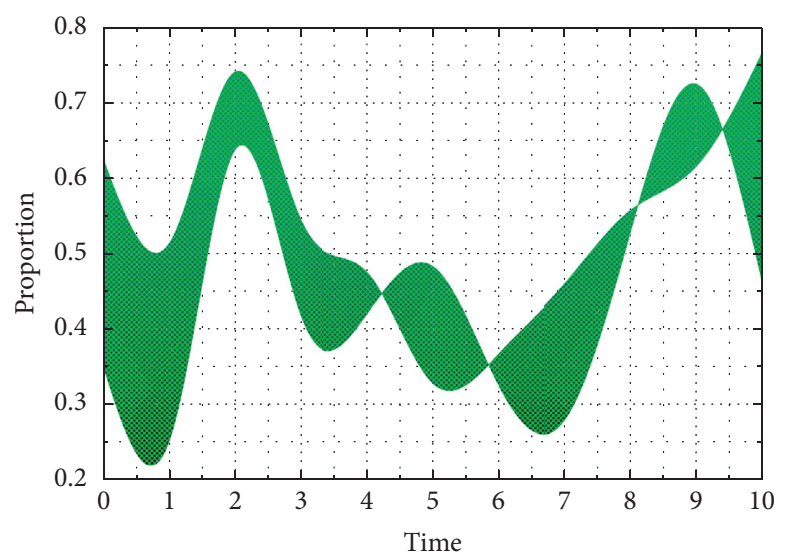

Figure 5: Dynamic evolution of state I system. 
government department group $x(t)$ and the proportion of compliance by the application platform group.

Figure 5 depicts the evolutionary trajectory of the behavior of the government department and the application platform when the public participation is low and the punishment is strong; with the increase of time $t$, the system eventually evolves to the stable point $(0,0)$. When the public participation is low, regardless of the level of punishment intensity of the government department to the application platform violation, the evolutionary stability result of the system is (negative regulation, violation) the government department to the application platform violation is stronger, and the application platform group evolves to the violation at a slower rate; that is, when the model parameters satisfy the condition of state, the size of the punishment intensity only affects the application platform group behaviour. When the parameters of the model satisfy the condition of state, the size of punishment only affects the speed of the evolution of the behavior of the application platform group from compliance to the violation and does not affect the result of system evolution. When the model parameters satisfy the condition of state, the size of public participation only affects the speed of evolution from negative regulation to positive regulation, but not the result of system evolution.

4.2. Analysis of the Results of the Optimization of the Governance Structure. The dynamic evolution process of the application platform group behaviour over time changes under the condition of meeting $x$ less than the threshold is shown in Figure 6. As can be seen from the figure, different initial values of $y$ show a monotonically decreasing trend over time, and even if the initial proportion of the application platform group's compliance behavior is as high as 0.8 , it will eventually converge to 0 , and the speed of convergence accelerates with the increase of the initial proportion. Therefore, when the proportion of government departments choosing "active regulation" is greater than 0.625, the behavior of the application platform group will eventually tend to violate the law. If $x>0.625$, we may take the value of $x=0.8$, and the initial values of application platform group compliance behavior are $y=0.2,0.4,0.6$, and 0.8 . The dynamic evolution of application platform group behavior over time when $x$ is greater than the threshold shown in Figure 6. As can be seen from the figure, different initial values of $y$ show a monotonic increasing trend over time, and even if the proportion of the application platform group compliance behavior has been as low as 0.2 , it will eventually converge to 1 , and the convergence rate slows down with the increase of the initial proportion. Therefore, when the proportion of government departments choosing "active regulation" is less than 0.625 , the behavior of the application platform group will eventually tend to be compliant.

In this paper, only the dynamic simulation diagram of the evolution path of the system and the influence of the degree of public participation, the intensity of punishment, and the initial proportion of the subject's behavior on the evolution results are given, and in fact, the evolution of the system when the values of other parameters are varied can be simulated by using the above method, which is not specifically listed here. As can be seen from Figure 7, the level of effort decreases with increasing the marginal effort cost and increases with increasing the intensity of government regulation, which on the one hand reflects the effectiveness of government regulation in restraining the opportunistic behavior of the application platform and on the other hand illustrates the constraining effect of marginal effort cost on increasing the level of effort of the application platform. Also, the smaller the value corresponds to a larger slope of the curve, indicating that $x$ is more sensitive to changes in the value, while the sensitivity gradually decreases as the value of $c$ increases; the larger the value of $p$, the larger the slope of the curve. Since the cost of government regulation follows the principle of increasing marginal cost, high level of regulatory intensity requires greater regulatory cost, and government departments should make appropriate tradeoffs between regulatory effectiveness and regulatory cost to choose the optimal regulatory intensity.

The reputation coefficient has a linear positive effect on effort level, and the marginal contribution rate always remains constant; public involvement degree has a nonlinear positive effect on effort level, and the marginal contribution rate increases with the increase of its value. The comparison analysis shows that, under the condition that the values of reputation coefficient and public involvement degree are equal, when the values of both are smaller than the horizontal coordinate of the intersection of the curves, the effect of reputation coefficient on improving the effort level is greater, and the effect of reputation mechanism to motivate the application platform to improve the effort level is better; while when the values of both are larger than the horizontal coordinate of the intersection of the curves, the motivational effect of public involvement degree is better than that of reputation mechanism, and the marginal growth rate is greater than zero. Therefore, we should pay attention to the flexibility of incentive selection at different stages, and make the optimal incentive strategy according to the specific effect of each incentive method.

As can be seen from Figure 8, the marginal cost of regulation and the cost of risk have nonlinear negative and linear positive effects on the intensity of government regulation, respectively, and the marginal contribution of the marginal cost of regulation decreases with increasing values, while the marginal contribution of the cost of risk always remains constant. The cost of regulation is an important factor considered by government departments in adopting regulatory strategies, and inappropriate regulatory strategies will lead to high regulatory costs, resulting in the waste of regulatory resources such as financial, material, and human resources of government departments and reducing regulatory efficiency. The intensity of government regulation directly affects the size of the cost of risk, and when the cost of risk increases, government departments need to increase the intensity of regulation to reduce the impact of uncertainty of exogenous factors and thus reduce the cost of risk.

The reputation coefficient and public participation have nonlinear positive and linear negative effects on the intensity 


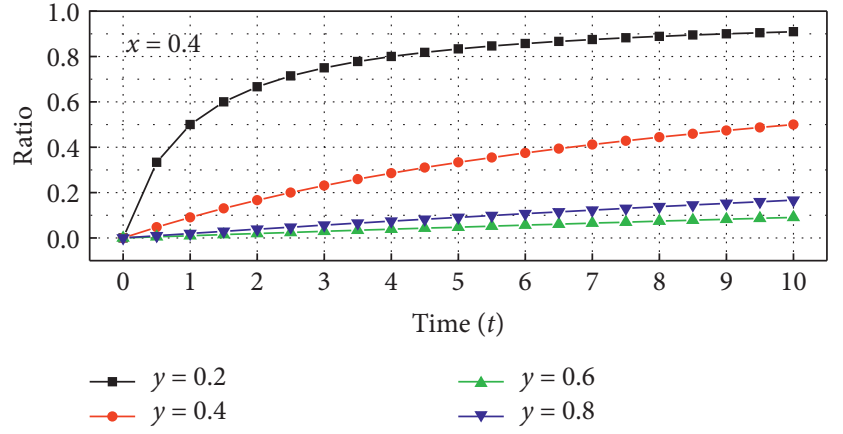

(a)

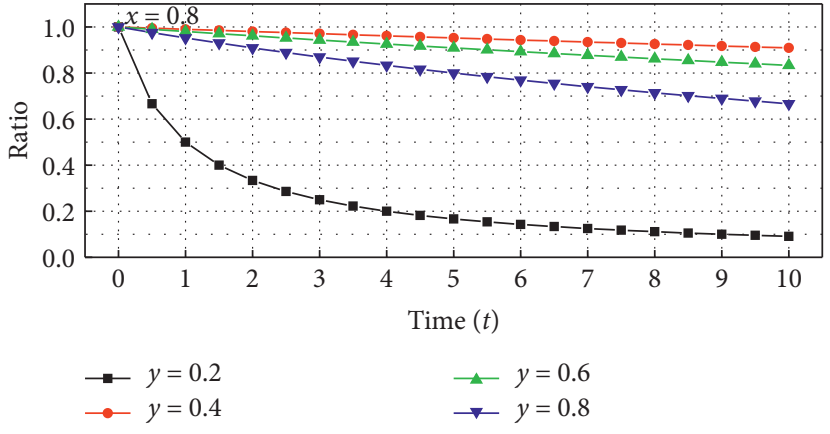

(b)

FIgURE 6: Application platform behavior evolution process.

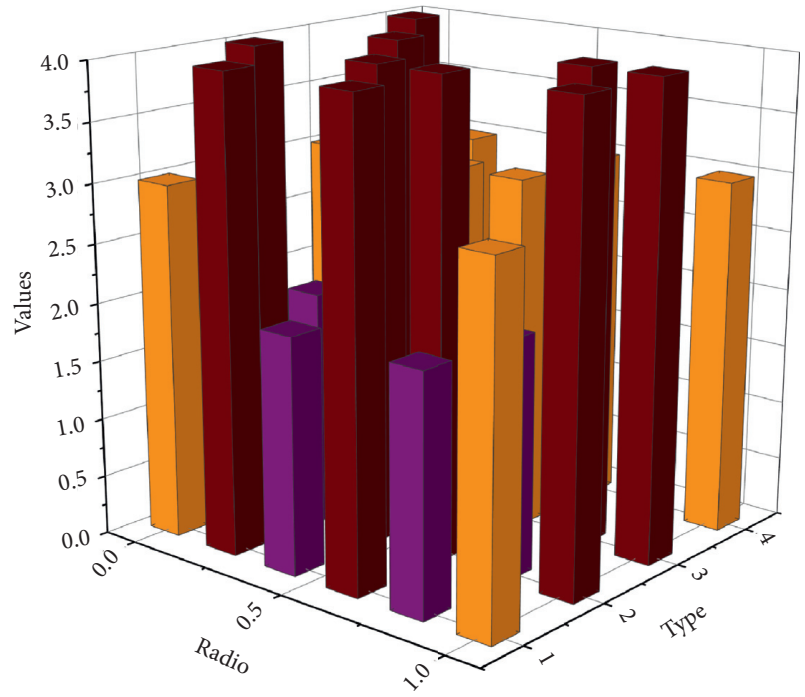

FIgURE 7: Reputation coefficient and public engagement.

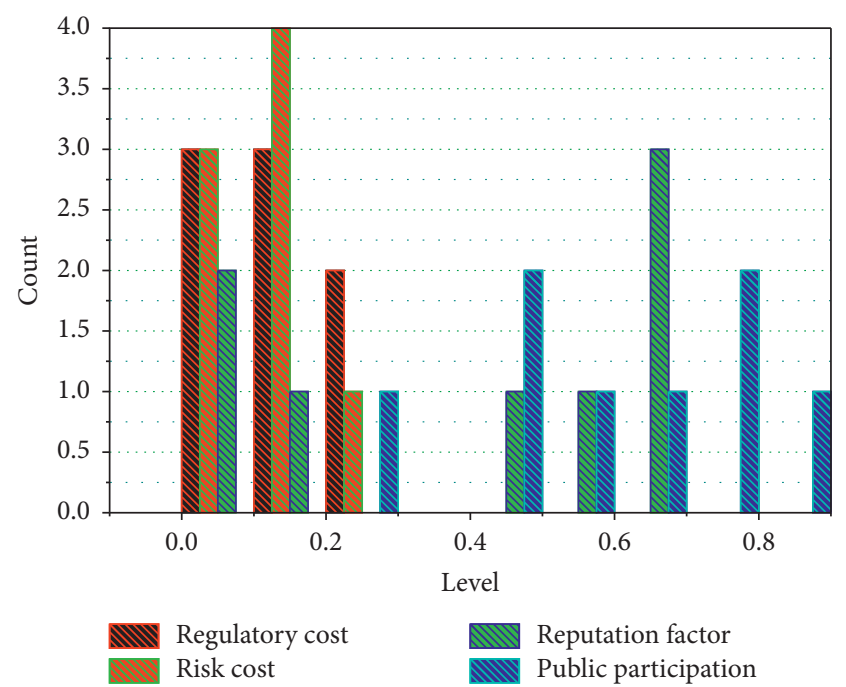

Figure 8: Marginal regulatory and risk costs, reputation coefficient, and public engagement. of government regulation, respectively, and the marginal contribution of reputation coefficient increases with increasing value, while the marginal contribution of public participation always remains constant. Although reputation mechanism positively contributes to the level of effort, it also increases the cost of risk, and a higher reputation coefficient indicates a higher risk cost, so the government should increase the intensity of regulation to reduce the risk cost. The negative relationship between the intensity of government regulation and the degree of public participation reflects the auxiliary supervisory role of the public, and the intensity of government regulation tends to zero when the degree of public participation tends to the maximum, and the public completely replaces the government department to exercise the supervisory right at this time.

\section{Conclusion}

Through the analysis of the dynamic evolution of the game relationship among the investment subjects of the smart urban community elderly collaborative governance, it is found that the investment subjects of the smart urban community elderly collaborative governance evolve from a single subject of the government to multiple subjects. In the face of the increasingly prominent mobile application security problems, government departments have made efforts to strengthen administrative supervision, public participation has been increasing, mobile application industry selfregulation norms have been launched one after another, and new media exposure has gradually increased, but a longterm mechanism of mobile application security governance with the participation of multiple parties has still not been formed, and it is extremely important to reveal the deepseated reasons for the formation of mobile application security problems. Against this background, this paper draws on relevant domestic and international research and combines it with actual practice to conduct a study on the strategy selection and incentive mechanism of mobile application security governance participants and to explore the response strategies of government departments, the public, 
and third parties to prevent collusion between application platforms and developers. Through the analysis of the motor mechanism of collaborative governance of smart urban communities, we conclude that the motivation mechanism is aimed at supporting the collaborative operation of smart urban communities for the elderly and evolves from administrative means to a hybrid collaborative approach based on communication, consultation, and financial support.

\section{Data Availability}

The data used to support the findings of this study are available from the corresponding author upon request.

\section{Conflicts of Interest}

The authors declare that they have no known competing financial interests or personal relationships that could have appeared to influence the work reported in this paper.

\section{References}

[1] G. Tran Thi Hoang, L. Dupont, and M. Camargo, “Application of decision-making methods in smart city projects: a systematic literature review," Smart Cities, vol. 2, no. 3, pp. 433-452, 2019.

[2] A. von Richthofen, L. Tomarchio, and A. Costa, "Identifying communities within the smart-cultural city of Singapore: a network analysis approach," Smart Cities, vol. 2, no. 1, pp. 66-81, 2019.

[3] T. Yigitcanlar, "Smart city policies revisited: considerations for a truly smart and sustainable urbanism practice," World Technopolis Review, vol. 7, no. 2, pp. 97-112, 2018.

[4] J. Wang, C. Jiang, K. Zhang et al., "Vehicular sensing networks in a smart city: principles, technologies and applications," IEEE Wireless Communications, vol. 25, no. 1, pp. 122-132, 2017.

[5] B. Anthony Jnr, "Smart city data architecture for energy prosumption in municipalities: concepts, requirements, and future directions," International Journal of Green Energy, vol. 17, no. 13, pp. 827-845, 2020.

[6] X. Chen, "The development trend and practical innovation of smart cities under the integration of new technologies," Frontiers of Engineering Management, vol. 6, no. 4, pp. 485502, 2019.

[7] H. Xu and X. Geng, "People-centric service intelligence for smart cities," Smart Cities, vol. 2, no. 2, pp. 135-152, 2019.

[8] S. E. Bibri and J. Krogstie, "Towards A novel model for smart sustainable city planning and development: a scholarly backcasting approach," Journal of Futures Studies, vol. 24, no. 1, pp. 45-62, 2019.

[9] M. Sookhak, H. Tang, Y. He et al., "Security and privacy of smart cities: a survey, research issues and challenges," IEEE Communications Surveys \& Tutorials, vol. 21, no. 2, pp. 1718-1743, 2018.

[10] K. Lin, C. Li, G. Fortino, and J. J. P. C. Rodrigues, "Vehicle route selection based on game evolution in social Internet of vehicles," IEEE Internet of Things Journal, vol. 5, no. 4, pp. 2423-2430, 2018.

[11] G. Javadzadeh and A. M. Rahmani, "Fog computing applications in smart cities: a systematic survey," Wireless Networks, vol. 26, no. 2, pp. 1433-1457, 2020.
[12] J. Xie, H. Tang, T. Huang et al., "A survey of blockchain technology applied to smart cities: research issues and challenges," IEEE Communications Surveys \& Tutorials, vol. 21, no. 3, pp. 2794-2830, 2019.

[13] V. Logvinov and N. Lebid, "Is the Smart cities of hybrid model of local government-The type III cities: four possible answers," Smart Cities and Regional Development (SCRD) Journal, vol. 2, no. 1, pp. 9-30, 2018.

[14] B. Anthony Jnr, S. Abbas Petersen, D. Ahlers, and J. Krogstie, "API deployment for big data management towards sustainable energy prosumption in smart cities-a layered architecture perspective," International Journal of Sustainable Energy, vol. 39, no. 3, pp. 263-289, 2020.

[15] D. Eckhoff and I. Wagner, "Privacy in the smart city-applications, technologies, challenges, and solutions," IEEE Communications Surveys \& Tutorials, vol. 20, no. 1, pp. 489-516, 2017.

[16] F. Zambonelli, F. Salim, S. W. Loke, W. De Meuter, and S. Kanhere, "Algorithmic governance in smart cities: the conundrum and the potential of pervasive computing solutions," IEEE Technology and Society Magazine, vol. 37, no. 2, pp. 80-87, 2018.

[17] R. Du, P. Santi, M. Xiao et al., "The sensable city: a survey on the deployment and management for smart city monitoring," IEEE Communications Surveys \& Tutorials, vol. 21, no. 2, pp. 1533-1560, 2018.

[18] I. Yaqoob, L. U. Khan, S. M. A. Kazmi et al., "Autonomous driving cars in smart cities: recent advances, requirements, and challenges," IEEE Network, vol. 34, no. 1, pp. 174-181, 2019.

[19] E. Keymolen and A. Voorwinden, "Can we negotiate? Trust and the rule of law in the smart city paradigm," International Review of Law, Computers \& Technology, vol. 34, no. 3, pp. 233-253, 2020.

[20] K. Xu, X. Wang, W. Wei, H. Song, and B. Mao, "Toward software defined smart home," IEEE Communications Magazine, vol. 54, no. 5, pp. 116-122, 2016.

[21] A. Zielonka, A. Sikora, M. Wozniak, W. Wei, Q. Ke, and Z. Bai, "Intelligent Internet of things system for smart home optimal convection," IEEE Transactions on Industrial Informatics, vol. 17, no. 6, pp. 4308-4317, 2021.

[22] W. Wang, N. Kumar, J. Chen et al., "Realizing the potential of the Internet of things for smart tourism with $5 \mathrm{G}$ and AI," IEEE Network, vol. 34, no. 6, pp. 295-301, 2020.

[23] L. Belli, A. Cilfone, L. Davoli et al., "IoT-enabled smart sustainable cities: challenges and approaches," Smart Cities, vol. 3, no. 3, pp. 1039-1071, 2020. 